\title{
(Des) Encontros entre a leitura da teoria linguística no curso de letras e o ensino da leitura na escola
}

\author{
THE RELATIONSHIP BETWEEN THE READING OF LINGUISTICS \\ THEORY IN THE COURSE OF LETTERS AND TEACHING OF THE \\ READING AT SCHOOL
}

\author{
Juliana Bertucci BARBOSA * \\ Marinalva Vieira BARBOSA ** \\ Acir Mário KARWOSKI ***
}

\begin{abstract}
Resumo: Neste artigo, apresentamos uma breve reflexão sobre o valor da leitura na nossa sociedade e os problemas relacionados ao ensino da leitura na escola e, consequentemente, na universidade. Além disso, discutimos alguns entraves que favorecem o fracasso da escola no ensino da leitura - na formação linguística do professor de língua portuguesa e o papel da universidade na manutenção desses entraves. Por fim, reconhecendo a importância da pesquisa em interface com a extensão, citamos uma proposta para minimizar os problemas de leitura: um projeto de pesquisa e extensão sobre leitura e produção de textos, desenvolvido com alunos de graduação do curso de Letras.

Palavras-chave: Leitura; Ensino Superior; Teoria Linguística.
\end{abstract}

Abstract: This article presents reflections on the value of reading in our society and the problems related to the teaching of reading in school and the university. Furthermore, we discuss some barriers (that favor the failure of the school to teach reading) of Linguistic training of the Portuguese language teacher and the

* Doutora em Linguística e Língua Portuguesa pela UNESP/Araraquara. Professor Adjunto do Curso de Letras da UFTM. Contato: julianabertucci@gmail.com.

** Pós-doutorado na UNICAMP; doutorado em Linguística (UNICAMP). Professor Adjunto UFTM. Contato: marinalvav@gmail.com.

*** Doutor em Linguística (UFPR). Professor adjunto UFTM. Contato: acirmario@letras.uftm.edu.br. 
role of the university in maintaining these barriers. Finally, recognizing the importance of research at the interface with the extension, we discussed a proposal to minimize the problems of reading: a research project and extension about reading and writing texts developed with graduate students of the course of Letters.

Key-words: Reading; Higher Education; Linguistics Theory.

\section{Apresentação}

Ler é uma atividade essencial para a sociedade contemporânea. Inúmeras tarefas dependem dela, como, por exemplo, pegar o ônibus certo, ler uma bula de remédio corretamente, escrever um bilhete (recado). No campo das produções visuais, as imagens, ícones, símbolos, gráficos e desenhos passaram a fazer parte do cotidiano mais comum. No campo da informática, os blogs, e-mails, salas de bate papo constantemente reconfiguram as práticas de leitura. A cada dia fica evidente que o estado de letramento só é alcançado quando aquele que se põe a dialogar com um texto sabe construir significados, perceber o valor dos múltiplos textos em contextos específicos, fazer inferências, construir conclusões a partir da leitura de diferentes gêneros.

Entretanto, por mais comum que possa parecer, a realização da leitura é extremamente complexa. A leitura representa um grande passo para aquisição do conhecimento, pois é por meio dela que se adquire uma percepção singular do mundo. Também contribui para o funcionamento e desenvolvimento do pensamento crítico, levando o leitor a questionar e avaliar o texto lido, dentro de um referencial próprio de seus conhecimentos, conceitos e valores. Diante disso, embora não seja tarefa restrita da escola, é inquestionável a importância da leitura em uma educação de qualidade. Porém, professores, quando ouvidos sobre as habilidades de leitura de seus alunos, sustentam discursos como os que seguem: "O professor de português teria que ganhar mais que os outros porque tem que corrigir textos: eles escrevem muita bobagem". "Fico pensando que eles não ouvem nada do que digo nas aulas de produção de textos". "É uma perda de tempo tentar ensinar esse povo a ler e escrever". "Não entendo o aluno que temos hoje, parece que ele não quer saber de nada que a escola ensina: ler então 
nem pensar". "No tempo em que estudei, eu amava ler e escrever". "Ainda bem que não sou professor de língua portuguesa". ${ }^{1}$

Esses enunciados não só evidenciam que diversos alunos saem do Ensino Médio com deficiências nessa habilidade, mas também demonstram concepções conflitantes sobre leitura e, principalmente, demonstram como essa atividade - quando realizada no interior da escola -, por alunos que já estão no Ensino Médio, são vistas, avaliadas pelos professores. As imagens que formam desse aluno é a de um sujeito incapaz de mobilizar a linguagem escrita para construir um projeto mínimo de dizer: o texto.

Se considerarmos que os enunciados acima fazem referência ao aluno que está no Ensino Médio, podemos acrescentar que esse mesmo aluno, quando adentra os cursos de graduação, muitas vezes, vai continuar apresentando as mesmas dificuldades relacionadas à leitura e à escrita.

Assim, como podemos observar com os argumentos expostos, embora haja um quase consenso em torno do fato de que saber ler é conhecimento essencial na nossa sociedade, há uma crise relacionada ao aprendizado da leitura que começa na escola e está adentrando a universidade. E vários são os seus pontos de sustentação: há um aluno que, como um enigma, oferece resistências e não adere ao projeto de leitura tal qual a escola deseja. Há um professor que não só tem dificuldades de construir explicações para os problemas que emergem nas produções de seus alunos, mas também não compreende esse sujeito aluno na relação com a temporalidade em que está inserido. Ou seja, no que concerne ao ensino da leitura, o professor tem dificuldades de lançar mão das diferentes teorias - linguísticas ou não -, para compreender esse sujeito que, de fato, é o seu grande interlocutor cotidiano no exercício da docência. Nas demais áreas de conhecimento, o professor, ao se defrontar com esse aluno que não lê, não escreve, opta por assumir que o declínio da escrita e da leitura é um dilema a ser enfrentado somente por aqueles que ensinam a língua portuguesa.

${ }^{1}$ Esses enunciados foram anotados durante pesquisa realizada, em 2005, por uma das autoras deste texto, em escolas do Estado de São Paulo. 
Considerando tal contexto, a universidade passa a ter "a obrigação" de proporcionar ao estudante uma formação que lhe dê condições de constituir-se como sujeito letrado, algo primordial ao futuro desempenho profissional desse estudante. A habilidade de leitura é essencial para o aluno universitário, pois seu sucesso no ensino superior está associado à sua maturidade em leitura, que pode ser melhorada, se diagnosticada apropriadamente. Nesse sentido, a universidade está diante de um desafio, pois não pode mais deixar a formação de leitores a cargo da escola e, ao mesmo tempo, precisa continuar insistindo para que a universidade passe a ser realmente um espaço de constituição de leitores preparados para transitar na sociedade contemporânea.

Focalizando a formação do professor de língua portuguesa, diversos estudos demonstram que o aluno de Letras, ${ }^{2}$ futuro ou já professor de língua portuguesa, também não apresenta o nível de leitura esperado para essa etapa de escolarização. Consequentemente, esse aluno, por ter dificuldade de transformar o que leu durante todo o seu curso de graduação, forma-se e continua a apontar um "abismo" entre leitura e o exercício do magistério, entre aquilo que se lê na universidade e a prática de ensino na escola. Seguindo esse panorama, o professor que está na escola pouco tem se servido das produções acadêmicas para construir reflexões e compreensões acerca dos problemas de leitura de seus alunos. Após o término do curso de Letras, vai para a escola e, logo nos primeiros momentos de exercício da docência, conclui que o que viu e ouviu na universidade, em termos teóricos, não lhe ajuda no exercício da prática de ensino (NEVES, 2002).

Daí surge a convicção de que a busca de solução para os problemas relacionados à constituição de leitores em nossa sociedade, não passa somente pela discussão crítica das práticas escolares de ensino, mas também pela análise crítica do papel da universidade na realização dessa tarefa. Especificamente, passa pela análise crítica acerca do modo como a universidade tem trabalhado para que o professor de língua portuguesa possa assumir, primeiro, a posição de sujeito letrado e, segundo, a posição de sujeito letrado com condições de também letrar.

\footnotetext{
${ }^{2}$ Neste artigo, focalizaremos somente a questão da leitura no curso de Letras.
} 
Seguindo esse ponto de vista, apresentaremos uma reflexão sobre a necessidade do professor de língua portuguesa mudar suas práticas pedagógicas referentes à leitura, para que essa habilidade passe a ser uma "ferramenta de trabalho" (PERRENOUD, 2008) e para que a teoria se transforme em efetiva, aliando o conhecimento teórico adquirido na universidade às vivências práticas, possibilitando transformar a teoria em situações problemas. Para ilustrar a nossa discussão, partiremos do papel da Linguística no curso de Letras. Inicialmente faremos uma sucinta volta ao passado, resgatando algumas discussões já realizadas sobre esse assunto. Em seguida, focalizaremos o cenário atual, o século XX, levantando algumas discussões e apontamento sobre o papel da Leitura, da Linguística e sobre a relação entre a teoria e a prática do professor de língua portuguesa. E, para finalizar, como resposta possível para a problemática exposta neste artigo - e levando em consideração a necessidade da pesquisa em interface com a extensão - citaremos o projeto de pesquisa e extensão, realizado na Universidade Federal do Triângulo Mineiro (UFTM), sobre leitura e produção de textos desenvolvido com alunos de graduação do curso de Letras.

\section{Os caminhos da Linguística na formação do professor/leitor no Curso de Letras: breve percurso histórico}

Desde sua introdução, nos currículos dos cursos de Letras na década de 1960, a Linguística ganhou espaço e se firmou fazendo-se valer pelo caráter científico das diversas linhas teóricas que engloba. Conquistou adeptos no cenário acadêmico e, consequentemente, passou a influenciar os rumos do ensino de língua materna no Brasil (DE PIETRI, 2003). Entretanto, se no meio acadêmico, desde o princípio, houve adesão quase que irrestrita às propostas e concepções dessa disciplina (RAJAGOPALAN, 2003), o mesmo movimento não foi adotado pelos professores dos níveis iniciais de escolarização. A entrada da Linguística na sala de aula sempre foi marcada por polêmicas e conflitos.

As polêmicas e conflitos assumiram rumos e estágios diferenciados. No início da década de 1980, a pergunta feita por Gebara, Romualdo e Alkimin (1984) acerca de como essa ciência podia 
ajudar o ensino da língua portuguesa denunciava a existência de problemas relacionados à inserção da disciplina nos currículos dos cursos de Letras. Os autores questionavam o modo apressado, despreparado e salvacionista que cercou sua adoção para trabalhar a formação do professor de língua materna. A pronta condenação do ensino da gramática tradicional e a assunção da Linguística à posição de elemento iluminador dos caminhos que se deveriam seguir gerou uma adesão indiscriminada, passando-se a ler as teorias inclusive nas salas de aula do Ensino Médio. O que se lia na universidade passou a ler lido também na escola.

$\mathrm{Na}$ mesma época e seguindo a mesma linha, Kato (1983) também fez uma análise acerca do que estava acontecendo e conclui que a relevância pedagógica da Linguística era indiscutível, mas muitos equívocos vinham sendo cometidos porque foram criadas propostas de ensino, inclusive para os cursos de Letras, em cima de "conceitos e princípios mal compreendidos" (KATO, 1983, p. 52). Isso teria provocado certa desilusão a respeito do valor pedagógico da Linguística. Da leitura apressada caminhou-se para a descrença na relevância das teorias.

Diante disso, nas décadas seguintes (anos de 1980 e 1990), houve um trabalho contínuo e intenso visando à criação e/ou o aperfeiçoamento de propostas sobre como a Linguística efetivamente podia se transformar em um recurso de construção do ensino da língua portuguesa, especificamente no ensino da leitura e da escrita (GERALDI, 1995; POSSENTI 1996; TRAVAGLIA 1996; ILARI 1980, 1983). Porém, cerca de 20 anos após o início desses esforços para fazer a Linguística efetivamente entrar na escola, Neves (2000; 2002), baseada em pesquisas desenvolvidas com professores do Estado de São Paulo, não só afirma que a formação linguística do professor de língua portuguesa continua sendo um problema que está longe de ter uma solução satisfatória, como também aponta a existência de um movimento de recrudescimento. Ou seja, segundo a autora, os professores do Ensino Fundamental e Médio, seguindo um caminho contrário ao da década de 1970, decidiram esquecer que um dia leram ou ouviram falar da Linguística e começaram a sinalizar um retorno ao ensino da gramática tradicional. Esta retoma a posição de elemento importante para o aprendizado da leitura e da escrita. 
O movimento apontado por Neves não é isolado. Estudos desenvolvidos em diferentes partes do Brasil sinalizam a existência de resistência e rejeição às teorias linguísticas (EMILIANO; ZANINE, 2005). Barbosa (2004) demonstra que alunos concluintes do curso de Letras (a maioria já exercendo o magistério) localizados nas regiões Norte e Sudeste não viam nas teorias um meio de estudo da língua portuguesa e muito menos um recurso de compreensão e construção de solução para o problema da leitura na escola. Em razão disso, os participantes da pesquisa afirmavam que na escola retomariam o ensino da gramática tradicional embora também não se concebessem como professores que sabiam gramática em razão da natureza teórica do curso.

Como a Linguística para se firmar elegeu a gramática tradicional como grande opositora (RAJAGOPALAN, 2003), a explicação quase unânime para esse problema, nos dias atuais, tem sido a de que os professores dos níveis iniciais de escolarização optam pela manutenção da perspectiva tradicional de ensino da leitura e da escrita em função do valor social da língua padrão, da resistência ao novo, da pressão da escola e da família para que se ensine regras gramaticais etc. Em suma, a busca de explicações tem sido em espaços exteriores à universidade, quase sempre não relacionada à questão da relação desse sujeito com os conhecimentos teóricos, e sempre baseada no pressuposto de que o professor, depois de passar pelo curso (ouvir sobre as teorias), deve apresentar condições de renovar sua prática na exata medida do que lhe foi transmitido em aulas e discussões expositivas.

Em pesquisas desenvolvidas em 2004 e 2005 por uma das autoras deste projeto, professores de língua portuguesa do ensino Médio sustentaram um discurso que nega a concepção de que a passagem pelos cursos de Letras é suficiente para mudar as práticas de ensino; e, principalmente, indiciam que a anunciada volta à gramática não se justifica somente pelo valor que esta assume como representante legítima da língua portuguesa, mas por que a constituição desse sujeito de saber que a universidade busca se quebra pela sua própria forma de realização. Vejamos o que diz uma professora do primeiro ano do Ensino Médio. 
durante o meu curso (.) é:::h/ eu vi muitas teorias linguísticas/ todo mundo vem aqui e fala das suas pesquisas (.) das suas teorias sobre a língua (.) mas aí de repente (..) a impressão que tenho é que o meu curso está me dando um monte de retalhos que eu terei que costurar tudo (.) o problema é que eu não tenho certeza se saberei costurar esse monte de retalhos quando estiver em sala de aula (.) eu não ensino pro meu aluno teoria sociolinguística (.) gerativa (.) análise do discurso (...) eu preciso ensinar ele falar ler e escrever/ éeeh disso/ é isso que tenho que ensinar pro meu aluno (..) que eu espero que esse curso fale $\backslash$ eu não acredito que ensinar gramática seja a solução mas também não sei o que fazer com as teorias que estou vendo no curso (graduando em Letras e também professor em 2005)

O aluno (e já professor), olhando para o conhecimento adquirido na universidade, não estabelece relações, não constrói leituras e identificações que possam pôr as teorias como recursos que lhe possibilitem entender e construir soluções para os problemas relacionados ao ensino da leitura e da escrita na escola. Sabe da sociolinguística, da análise do discurso etc., mas, diante dos problemas plurais, heterogêneos que marcam o ensino dessas atividades, o saber teórico e a prática não têm pontos de convergência; ou não apresentam possibilidades de costuras conforme enunciado. Esses discursos demonstram que não há uma relação simplista entre preparação teórica (aprendizado das teorias) e inovação da prática. Entre uma e outra, instala-se a opacidade derivada da constituição desse sujeito de saber e do efetivo diálogo que trava com as situações de ensino que vivencia na universidade.

Segundo Neves (2002), as posições assumidas pelos graduandos em Letras apontam para dois pontos de sustentação desse discurso: um está no lugar de partida do professor de língua materna - a universidade - e outro está no lugar de chegada - a escola de Ensino Fundamental e Médio. O graduando vem para o curso em busca de um conhecimento específico e ao retornar para a escola, diante do que viu, ouviu e considera que aprendeu na universidade, assume que o conhecimento visto no decorrer do curso não tem nada a ver com o que deve fazer nas escolas, voltando "a trabalhar com a malfadada e malfalada gramática tradicional” (NEVES, 2002, p. 255). 
Para a autora, esse gesto fala de um desencontro, traz à tona uma realidade: entre saberes universitários e práticas escolares ainda não foi construído uma passarela que permita ir e vir. A compreensão de que a linguística é, indiscutivelmente, necessária ao professor de língua materna fica no plano teórico. Nesse ponto, surge uma pergunta também comum: então o que é feito com os conteúdos linguísticos estudados no curso de Letras? Parece que tal estudo configura-se como uma obrigação curricular que não tem efetiva aplicabilidade na prática do professor. Como resultado desse distanciamento, ainda segundo Neves (2002), os professores, ao deixar os cursos de Letras, validam a crítica ao modelo de ensino tradicional feito pela universidade, reconhecendo as suas deficiências, mas no seu cotidiano voltam a ancorar-se nas práticas já estabilizadas, amparando-se também nos modelos de ensino, nos modos de trabalho, nos conselhos dados pelos professores mais antigos.

\section{Formas de ler a teoria linguística na universidade e alimentação desse desencontro}

Nos cursos de Letras, nas aulas que se discute, por exemplo, ensino da leitura e da escrita, não é raro alunos de Letras demonstrarem que não estão "necessariamente convencidos que as gramáticas tradicionais - objetos de vilipêndio dos linguistas que, desde o nascimento da nova ciência, vêm usando os gramáticos como uma espécie de saco de pancadas - são dispensáveis ao ensino" da leitura e da escrita (RAJAGOPALAN, 2003, p. 10). Segundo o autor, isso é também um indício de que o diálogo proposto nos cursos de Letras não ocorre efetivamente, uma vez que não estamos conseguindo construir uma visão sólida sobre como o professor de língua materna deve atuar no seu campo de trabalho. Além da dificuldade de diálogo, isso contribui para um outro equívoco sério: a crença de que se não se deve ensinar as regras normativas, tudo deve ser aceito e nada deverá ser feito, por exemplo, com o texto do seu aluno, pois a Linguística aceita tudo, como aparece na afirmação de um aluno de Letras de uma Universidade pública do Estado de São Paulo: 
Os conhecimentos da língua portuguesa dão caminhos diferentes para a pessoa. Fico pensando: como será que vai ficar o ensino da gramática normativa daqui a uns dez anos se a Lingüística aceita tudo o que a gramática não aceita. Hoje não podemos ensinar a gramática, temos que ensinar Lingüística. Imagino que a gramática normativa não vai existir, ela vai ser reformulada. Hoje a gramática normativa leva em consideração as regras, o português correto. Se isso acontecer, se a gramática normativa deixar de existir, acho que será um caos, porque vai valer nós foi, nós tá voltando. Imagino que vai ser um caos, mas vai ser a nossa realidade. Mas a universidade defende isso, né? Não devemos mais ensinar gramática, temos que trabalhar com o texto, com um ensino moderno. Não consigo entender como isso pode ser feito sem a gramática.

Há um claro equívoco na leitura da teoria e, como demonstra o enunciado, não ter um entendimento claro do que seja o estudo da Linguística, seus objetivos e finalidades, como afirma Rajagopalan, deixa os alunos "perplexos", produzindo efeitos de incompreensão acerca da relação desta com o ensino de língua portuguesa. Os alunos de Letras, na realidade, não conhecem esse objeto (a gramática) que lhes é apresentado mediante noções vagas e abstratas, pois os estudos metalinguísticos feitos na escola não oferecem a base para que apresentem a mesma familiaridade com a chamada gramática tradicional; o que comumente possui os críticos desta. Com isso, o aluno entra num espaço de conflito sem o letramento teórico necessário para sustentar sua própria leitura da teoria. Rajagopalan (2003, p. 11) afirma:

Quando, nós, os lingüistas de hoje, começamos os nossos estudos iniciais no campo da lingüística, trinta, vinte, ou mesmo dez anos atrás, tínhamos uma boa base nos princípios da gramática tradicional. $\mathrm{Na}$ verdade, a nossa conversão à nova ciência se deu precisamente em virtude do fato de que éramos capazes de cotejar o velho e o novo e, dessa forma, chegar às nossas próprias conclusões a respeito da superioridade da lingüística moderna em relação à gramática tradicional e à necessidade de 
rever crenças fortemente arraigadas e por isso mesmo raramente postas sob olhar crítico. Acontece que os nossos alunos, principalmente aqueles que estão em cursos introdutórios, com freqüência não têm a mesma familiaridade com a chamada gramática tradicional e, muito menos, com os princípios e preceitos que norteavam o trabalho por trás daquelas obras.

O aluno conhece as críticas sem, no entanto, conhecer efetivamente o objeto de crítica. Tal afirmação não significa adotar a defesa de que, nos cursos de Letras, deve ter um ensino de língua que atenda ao que é demandado pelo graduando, mas demonstra que esse objeto de crítica não está sendo bem contextualizado dentro das teorias linguísticas, o que além de não garantir a adesão do graduando, tem posto em confronto conhecimentos não equivalentes. Significa afirmar que os modos de ler a teoria linguística ainda continua provocando interpretações equivocadas e similares àquelas que foram feitas no início da década de 1980. Construir a validade da Linguística em cima das falhas da gramática coloca esta última no lugar de uma ciência oposta àquela.

Essas oposições têm relevância no discurso de resistência às teorias e de sedimentação da gramática normativa e, principalmente, na manutenção desta como um recurso de ensino da leitura na escola. $\mathrm{E}$ isso não pode ser visto como defesa da normatividade, mas como defesa do que se compreende como desempenho dos usos da linguagem. O graduando continua tendo a gramática como parâmetro para a conformação a leitura e da escrita aos padrões vigentes e aceitos na sociedade. Consequentemente, o encontro com a Linguística passa então a ser visto com surpresa, como o inesperado e até mesmo desnecessário, considerando ser o curso voltado para a formação de professores. Mesmo aqueles que não pretendem atuar como professores cobram o ensino da gramática. Fazer Letras corresponde à expectativa de tornar-se conhecedor da gramática, de apresentar um domínio fundamental para a constituição de um sujeito leitor e escritor. Esse conjunto de representações elaboradas e partilhadas por uma memória coletiva é o ponto de ancoragem primeiro dentro do curso.

Além disso, a Linguística está situada em um espaço mais restrito - a universidade -, portanto não adquire o mesmo status (ou não 
desfruta da mesma popularidade) da chamada gramática tradicional. $\mathrm{O}$ aluno de Letras não tem, pelo menos num primeiro momento, nenhuma expectativa de se tornar um linguista. Essa é uma posição que, no interior da graduação, considerando o fato de que pretende ser professor ou se busque qualquer outro campo profissional, não se privilegia.

Interpretando a partir do que é dado no contexto do curso, ambas, gramática normativa e Linguística, são igualadas, passam a ser lidas e interpretadas como campos de conhecimentos que devem apresentar unidade. Isso cria uma interface complexa, pois se apaga o fato de que dentro da palavra Linguística estão presentes várias maneiras de conceber e tratar a linguagem e que a gramática de uma língua compõe as preocupações da Linguística. Apaga-se também o fato de que dentro desse campo é natural filiar-se a uma linha teórica, e não a outras. Ser um linguista, necessariamente, não significa dominar todas as teorias que estão sob essa denominação.

A oposição entre gramática normativa e Linguística - sustentada pela leitura que coloca aquela como forma de apresentação desta reforça a compreensão específica que o aluno já traz para a universidade sobre o estudo da Língua portuguesa. Constrói-se uma compreensão de substituição de uma pela outra, o que leva ao fortalecimento de uma leitura de senso comum de que a Linguística aceita tudo ou de que as teorias linguísticas não têm nada a ver com o que se ensina na escola.

A leitura e interpretação da Linguística como campo homogêneo, leva o aluno de Letras a acreditar que é preciso conhecer a Linguística como lhe é cobrado que conheça a gramática. Diante de tal comparação, as teorias passam a ser vistas como impossíveis de serem dominadas, transformadas em saber prático e que auxilie no ensino da leitura na escola. Não sabendo ler a teoria também não tem recursos para ler e construir respostas para os problemas postos pelo contexto escolar. A impossibilidade de composição de um saber menos disperso leva-o à conclusão de que tais teorias não oferecem condições suficientes para dar conta dos desafios e dificuldades que serão enfrentados no processo de ensino da língua portuguesa, pois vê a Linguística como teorias que tratam de muitas coisas, mas não do que deve ser ensinado na escola. 
Diante disso, os recortes teóricos feitos por cada professor no decorrer do curso e as razões de cada disciplina - sua ligação com o trabalho efetivo de docência na escola - parecem ser o elo que não se estabelece. A diferença das concepções entre o que é feito na escola e o que é vivenciado na universidade acontece de forma tão contundente que a ruptura apontada pelo graduando pode estar funcionando como justificativa para a continuidade do trabalho com o ensino da gramática normativa. "Despejar esses conteúdos - mesmo facilitados - sem prover a sua integração na ação pedagógica é simplesmente sacudir a poeira e jogá-la sobre alguém" (NEVES, 2002, p. 232). É jogar para o aluno de Letras um universo de conhecimento e esperar que ele estabeleça as pontes necessárias. Algo que não vem acontecendo. Uma visão da Linguística como um todo não se efetiva, isto é, o aluno não consegue compor uma leitura teórica menos dispersa, e por isso acaba por juntar sob a denominação Linguística um conjunto heteróclito de fenômenos e de teorias, absolutamente descosturados tanto do processo de produção científica quanto das possibilidades abertas de redefinição do ensino da leitura na escola.

\section{Apontamentos sobre possíveis formas de ler a teoria linguística no confronto com a prática}

Conforme demonstrado nos tópicos anteriores, desde a inserção da Linguística na grade curricular de Letras, encontramos, depois de tantos anos de discussão, o mesmo cenário: a dificuldade do aluno de Letras em ler a teoria e transformar, compreender o que lê nas disciplinas de Linguística na universidade. Continuamos encontrando perguntas como as apontadas por Neves: "O que fazer com a Linguística que aprendi no curso de Letras?”.

Estamos diante de uma séria questão: no ambiente universitário o aluno (futuro professor) tem dificuldade de extrair de cada teoria tópicos importantes quando necessário, tem dificuldade de construir a sua "própria" leitura ou sua própria concepção de ensino a partir do que leu, viu e ouviu na universidade. Para que cada um consiga fazer esse movimento, é necessário que, antes de mais nada, aprenda a ler, compreender os sentidos, fazer recortes, extrair, tirar conclusões e a partir disso construir seus próprios sentidos/conhecimentos. 
Diante desse cenário, seguindo as propostas de Perrenoud (2008), podemos afirmar que um dos desafios centrais da universidade no século XXI é:

(i) buscar alternativas de intervenção nas práticas de leitura e de escrita, visando à formação de sujeitos críticos;

(ii) ampliar as reflexões sobre a leitura e a escrita e, principalmente, sobre o possível "abismo" existente entre leitura-escrita e exercício do magistério, entre aquilo que se lê na universidade e a prática.

Como seguir tal caminho sem permitir que se continue efetuando a separação entre teoria e prática? É inaceitável que reflexões, debates e discussões transmutem-se em regras de atuação, "cartilhas". Novas concepções de letramento têm trazido novos paradigmas às práticas de ensino da linguagem. Na perspectiva do letramento, não basta ser alfabetizado - entendendo-se por esse conceito a aquisição do código escrito, a capacidade de decodificar/codificar - é necessário ser letrado (ou estar alfabetizado), entendendo como apropriação dos usos sociais da leitura, tornando própria a prática com a leitura, compreendendoa, interpretando-a, respondendo as demandas sociais. É preciso estar/ ser alfabetizado/letrado; é preciso alfabetizar letrando (SOARES, 1998).

Nesse sentido, cabe também fazer do curso de Letras lugar para o desenvolvimento de eventos e práticas de letramento do futuro professor de língua portuguesa. Coadunando com Batista (1990, p. 41), o que são as atividades nas aulas de processos de aprendizagem da leitura e escrita senão leitura e escrita sobre a leitura e a escrita? Assim, acreditamos que é necessário provocar no aluno/professor o pensamento reflexivo, que permita a construção de conhecimento na multiplicidade de saberes/experiências, levando-o a reconhecer-se como sujeito produtor de conhecimento e cultura.

Perrenoud (1993; 1996; 1999), ao discutir a necessidade de mudanças nos currículos universitários, afirma que, no tradicional modelo de formação, o futuro professor desenvolve uma relação com o saber e com a futura profissão que não o incita à reflexão, o que reforça o discurso de que os saberes acadêmicos não ajudam no processo de ensino. Ou seja, segundo o autor, o contrato e os objetivos de uma formação ligada ao paradigma reflexivo não são suficientemente explicitados e trabalhados para permitir a construção de uma prática docente reflexiva e critica. 
Assim, os impasses que cercam a formação linguística do professor de língua portuguesa não estão ligados somente aos valores e representações que carregam sobre o que seja o ensino da escrita e da leitura, mas também estão ligados à forma como os saberes são apropriados, incorporados e subjetivados ao longo do curso. A qualidade do ensino da leitura e da escrita na escola não depende somente do conhecimento teórico do professor, mas também da vivência deste como sujeito que escreve e que lê, uma vez que a formação é uma só, teórica e prática ao mesmo tempo, assim como reflexiva, crítica e criadora de identidade. $\mathrm{O}$ trabalho com a leitura e a escrita é uma prática complexa que não se realiza de forma eficiente quando reduzida à aplicação de um determinado saber.

Diante desse problema, temos defendido que a pesquisa em interface com a extensão é um meio de aliar conhecimento prático ao conhecimento teórico. Permite construir uma aprendizagem por problemas, que não é o mesmo que a formação pela prática. O aprendizado por problemas permite ao futuro professor buscar conceitos, teorias ou ferramentas para resolver o problema com mais recursos. Ou seja, os aportes teóricos e metodológicos passam a ser, efetivamente, meios de construção de respostas para as dificuldades de ensino e aprendizagem, uma vez que são compreendidos no confronto com situações locais e que não se configuram como abstrações teóricas.

A atual universidade, ao adotar uma formação generalista, baseada na "orelhada", ensina o professor em formação a servir de porta-voz de terceiros, sob cujos significados se aliena, em um movimento de quase total colagem e, consequentemente, leva à formação de um profissional com pouca autonomia intelectual. A educação que permita ao futuro professor de língua portuguesa produzir seu próprio conhecimento, quando no exercício da docência, implica num deslocamento de sua posição subjetiva e num transformarse. Aquele que está em formação precisa, nas vivências formativas, aprender mobilizar os saberes da cultura e, colocando seu corpo e sua singularidade em jogo, em diálogo com os saberes que lhes são dados, consiga produzir, por sua vez, novos significados, novos sentidos.

A formação do professor de língua portuguesa deve se dar, desde seu início, por meio de um tipo de exercício teórico e prático 
que possibilite a reflexão sobre seu campo de conhecimento de modo que possa ter, com isso que será a sua prática, uma relação dialógica, mediada pelas teorias que viu e ouviu durante o curso de Letras.

Assim, acreditamos que uma das atividades que pode ser elaborada no ambiente universitário para superar as dificuldades apresentadas neste artigo seja a pesquisa em interface com a extensão. Uma tentativa, e exemplo disso, é o projeto de extensão e pesquisa desenvolvido na UFTM, intitulado "A produção de texto no ambiente universitário", ${ }^{3}$ que busca desenvolver um trabalho teórico-prático, estabelecendo uma relação entre o sujeito de conhecimento e o próprio objeto de conhecimento, neste caso, o ensino da leitura e da escrita.

Este projeto possibilita a criação de espaço didático onde o trabalho com produções textuais e as leituras teóricas complementarão a formação do aluno-participante, levando-o a vivenciar, durante o período de formação/graduação, as atividades relacionadas à docência. Tentamos responder, por meio deste projeto, principalmente as seguintes questões: (i) como formar um professor produtor de texto e, consequentemente, capacitado para transformar seus alunos também em sujeitos produtores de textos?; (ii) como associar teoria à prática?; (iii) como levar o aluno a aplicar/refletir o conhecimento lido durante as aulas do curso de Letras?

Em suma, ao propor este projeto de extensão, buscamos criar condições para que o aluno do curso de licenciatura em Letras da UFTM vivencie situações de trabalho com o texto (produzido por alunos das demais licenciaturas e Serviço Social) que o auxilie a compreender as teorias estudadas ao longo do curso - principalmente, os conceitos abordados em Língua Portuguesa I e II -, e lhe proporcione condições de refletir, ainda na universidade, sobre estratégias e materiais necessários ao ensino da leitura e escrita na escola. Partimos do princípio de que é possível, a um só tempo, o aluno/ participante começar a manusear o texto do outro (aluno), levantar

${ }^{3}$ Coordenado pela professora de Leitura e Produção de Texto dos Cursos de Licenciaturas e Serviço Social da UFTM, Dr. ${ }^{a}$ Marinalva Vieira Barbosa e pela professora de Língua Portuguesa do Curso de Letras da UFTM, Dr. ${ }^{a}$ Juliana Bertucci Barbosa. 
problemas e refletir sobre possíveis soluções para os problemas encontrados.

Mediante os argumentos expostos, entendemos que atitudes/ atividades como essas - como as do projeto de extensão citado - são importantes para auxiliarem na superação da dicotomia teoria e prática que ainda é tão vigente na escola. Por meio da prática de leitura teórica e confronto com produções textuais, trabalhos como esses podem contribuir na construção de conhecimentos importantes à reflexão e à compreensão dos desafios relacionados ao ensino da leitura (e da escrita) na escola.

\section{Considerações finais}

Como mencionado no início deste artigo, a leitura representa um grande passo para aquisição do conhecimento, pois é por meio dela, que se adquire uma percepção singular do mundo. Além disso, oferece também uma contribuição para o funcionamento e desenvolvimento do pensamento crítico, levando o leitor/escritor a questionar e avaliar o texto lido/escrito, dentro de um referencial próprio de seus conhecimentos, conceitos e valores. Como essa exposição, buscamos refletir sobre o caminho da formação do professor, do caminho que entrecruza experiência, memória, história, leitura e escrita, múltiplos fios e vozes de uma rede tecida coletivamente.

Ilustramos, citando o nosso projeto de extensão, a necessidade de elaborar meios de levar o aluno-professor a construir uma ponte entre o que ele lê/escreve na universidade e o que se ensina na escola. $\mathrm{O}$ aluno-professor manuseando o texto do outro (aluno), aplicando os conhecimentos adquiridos por meio da leitura, terá que levantar problemas e refletir sobre possíveis soluções para os problemas encontrados.

Acreditamos que muitas outras questões ainda devam ser abordadas sobre esse assunto, Entretanto, o que tentamos salientar é a importância de se buscar diferentes recursos para provocar no aluno/ professor uma leitura reflexiva, que permita a construção de conhecimento na multiplicidade de saberes/experiências, levando-o a se reconhecer como sujeito produtor de conhecimento e de cultura. 


\section{Referências}

BAKHTIN, M. Marxismo e filosofia da linguagem. Trad. Michel Lahud; Yara Frateschi Vieira. São Paulo: Hucitec, 1995 [1929].

BARBOSA, M. V. Entre o sim e não, a permanência: o discurso do graduando em Letras sobre o ensino de língua materna. 2004. 143f. Dissertação (Mestrado em Linguística) - Universidade Estadual de Campinas, Campinas.

BARBOSA, M. V. et. al. Ensino de língua portuguesa. São Paulo: Thomson, 2008.

BATISTA, A. A. G. Aula de Português: discurso, conhecimento, escola. 1990. 360f. Dissertação (Mestrado em Educação) Universidade Federal de Minas Gerais, Belo Horizonte.

. Os professores são não leitores? In: MARINHO, M.; SILVA, C. S. R. (Orgs.). Leituras do professor. Campinas: Mercado de Letras, 1998.

DE PIETRI, E. A constituição do discurso da mudança do ensino de língua materna no Brasil. 2003. 202f. Tese (Doutorado em Linguística Aplicada) - Universidade Estadual de Campinas, Campinas.

EMILIANO, S. R.; ZANINE, M. O ensino da gramática nos cursos de Letras: diagnóstico de uma realidade. In: SEMINÁRIO DO CENTRO DE ESTUDOS LINGÜÍSTICOS E LITERÁRIOS DO PARANÁ, 17., Guarapuava, 2005. Anais ... Guarapuava: 2005. 1 CDrom.

GEBARA, E.; ROMUALDO, J. A.; ALKMIN, T. M. A lingüística e o ensino de língua portuguesa. In: GERALDI, J. W. (Org.). O texto na sala de aula: leitura \& produção. Cascavel: Assoeste, 1984.

GERALDI, J. W. (Org.). O texto na sala de aula: leitura \& produção. Cascavel: Assoeste, 1991. 
. Portos de passagem. São Paulo: Martins Fontes, 1995.

. Linguagem e ensino - exercícios de militância e divulgação. Campinas: ALB/Mercado das Letras, 1996.

ILARI, R. Lingüística e ensino da língua. Revista do Instituto de Estudos Brasileiros, n. 22, São Paulo, p. 19-26, 1980.

. A Lingüística e o ensino da Língua Portuguesa. São Paulo: Martins Fontes, 1986.

KATO, M. A. O ensino de línguas após a implantação da lingüística. Boletim da Abralin, p. 51-59, 1983.

KRAEMER, M. A. D. Gramática: um igapó estagnado a margem da língua? Revista Letra Magna, a. 3, n. 4, p. 1-10, jul./dez. 2006.

LARROSA J. Experiência e pobreza. . Linguagem e Educação depois de Babel. São Paulo: Autêntica, 2004.

NEVES, M. H. A gramática: conhecimento e ensino. In: AZEREDO, J. C. (Org.). Língua portuguesa em debate: conhecimento e ensino. Petrópolis : Vozes, 2000. p. 52-73.

A gramática: história, teoria e análise, ensino. São Paulo: EDUNESP, 2002.

PERRENOUD, P. Práticas pedagógicas, profissão docente e formação. Perspectivas Sociológicas. Lisboa: Dom Quixote, 1993.

. Enseigner: Agir dans l'urgence, décider dans l'incertitude Savoirs et compétences dans un metier complexe. Paris: ESF Editeur, 1996.

. Formar professores em contextos sociais em mudança: prática reflexiva e participação crítica. Revista Brasileira de Educação Crítica, Anped, n. 12, p. 5-21. set./dez. 1999. 
. et. al. As competências para ensinar no século XXI: a formação dos professores e o desafio da avaliação. Porto Alegre: Artmed, 2008.

POSSENTI, S. Por que (não) ensinar gramática na escola. Campinas: ALB/Mercado das Letras, 1996.

. Indícios de autoria. Questões para analistas do discurso. São Paulo: Parábola, 2009.

RAJAGOPALAN, K. Por uma lingüística crítica: linguagem, identidade e a questão ética. São Paulo: Parábola, 2003.

SOARES, Magda. Letramento: um tema em três gêneros. Belo Horizonte: Autêntica, 1998.

TRAVAGLIA, L. C. Gramática e interação: uma proposta para o ensino de gramática no $1^{\circ}$ e $2^{\circ}$ graus. São Paulo: Cortez, 1996.

VIEIRA, S. R.; BRANDÃO, S. F. Ensino de gramática: descrição e uso. São Paulo: Contexto, 2008. 